\title{
CD117 expression in breast phyllodes tumors correlates with adverse pathologic parameters and reduced survival
}

\author{
Wai Jin Tan ${ }^{1,2}$, Aye Aye Thike ${ }^{1}$, Sie Yong Tan ${ }^{1}$, Gary M-K Tse ${ }^{3}$, Min-Han Tan ${ }^{4}$, \\ Boon Huat Bay ${ }^{2}$ and Puay Hoon Tan ${ }^{1,2,5}$ \\ ${ }^{1}$ Department of Pathology, Singapore General Hospital, Singapore; ${ }^{2}$ Department of Anatomy, Yong Loo Lin \\ School of Medicine, National University of Singapore, Singapore; ${ }^{3}$ Department of Anatomical and Cellular \\ Pathology, Chinese University of Hong Kong, Hong Kong; ${ }^{4}$ Institute of Bioengineering and Nanotechnology, \\ Singapore and ${ }^{5}$ Duke-NUS Graduate Medical School, Singapore
}

\begin{abstract}
CD117 (c-kit) is a type III receptor tyrosine kinase encoded by the KIT gene. Deregulation of expression and mutations in the gene are implicated in various tumors. Reports of CD117 expression in phyllodes tumors have been controversial. We aim to investigate the protein expression of CD117 and mutations in the KIT gene in phyllodes tumors, and correlate the findings with pathological parameters and clinical outcome. A total of 272 cases were included in this study. CD117 expression was investigated by immunohistochemistry on tissue microarray sections. Toluidine blue staining was performed to indicate mast cells. Overall, $28(10 \%)$ cases were CD117 positive. CD117 expression was significantly associated with tumor grade $(P<0.001)$, increased stromal hypercellularity $(P=0.003)$, stromal atypia $(P=0.01)$, and stromal mitotic activity $(P<0.001)$, permeative microscopic margins $(P=0.002)$, and presence of hemorrhage $(P=0.001)$. Expression was also associated with poorer overall survival $(P=0.003)$. Nineteen cases were further selected for mutation screening through the Affymetrix OncoScan platform. No mutation of the KIT gene was found. Despite a lack of mutations in the $K I T$ gene, CD117 protein expression is associated with unfavorable pathological parameters and poorer prognosis, suggesting an underlying role in the biology of phyllodes tumors.
\end{abstract}

Modern Pathology (2015) 28, 352-358; doi:10.1038/modpathol.2014.111; published online 12 September 2014

CD117 (also known as c-kit) is a type III receptor tyrosine kinase encoded by the KIT gene. It is characterized by an extracellular domain containing five immunoglobulin-like repeats (encoded by exon 9), a transmembrane domain, a juxtamembrane domain (exon 11), and two intracellular tyrosine kinase domains (exons 13 and 17). On binding of KIT ligand at the extracellular domain, CD117 is activated and this initiates various downstream signaling pathways mediating cell survival, migration, and proliferation depending on the cell type. ${ }^{1}$ Since the KIT gene was identified in the 1980s as a proto-oncogene, it has been implicated in various tumors including gastrointestinal stromal tumors (GISTs), ${ }^{2}$ colon cancer, ${ }^{3}$ and melanomas. ${ }^{4}$

Correspondence: Dr PH Tan, MD, FRCPA, Department of Pathology, Singapore General Hospital, 20 College Road, Academia, Diagnostics Tower, Singapore 169856, Singapore.

E-mail: tan.puay.hoon@sgh.com.sg

Received 1 May 2014; revised 28 June 2014; accepted 28 June 2014; published online 12 September 2014
Phyllodes tumors are fibroepithelial neoplasms of the breast, characterized by a double-layered epithelial component arranged in leafy fronds formed by hypercellular spindle-cell stroma. They are classified into benign, borderline, and malignant grades on the basis of microscopic features of the stromal component as recommended by the World Health Organization (WHO) classification of tumors of the breast. ${ }^{5}$ Reports of CD117 expression in phyllodes tumors vary in the literature, with some documenting overexpression of CD117 in malignant phyllodes tumors, ${ }^{6,7}$ whereas others found negative or weak expression observed across all grades of phyllodes tumors. ${ }^{8,9}$ Data on prognosis of CD117-expressing phyllodes tumors are scanty, with two studies reporting an association with tumor recurrence. ${ }^{10,11}$ Investigations into KIT mutations in phyllodes tumors are even fewer, with two studies conducted in Asian cohorts revealing opposing findings. ${ }^{11,12}$

The objective of this study was to investigate protein expression and mutational status of CD117 in phyllodes tumors diagnosed in a single institution 
in Singapore; and to correlate the findings with pathologic parameters and clinical outcomes.

\section{Materials and methods}

\section{Patients and Tumors}

Phyllodes tumors diagnosed at the Department of Pathology, Singapore General Hospital from January 2003 to December 2010 were included in this study. The study received approval from the Centralized Institutional Review Board. Tumors were classified into benign, borderline, and malignant on the basis of histological features according to the WHO classification of breast tumors as previously described. ${ }^{13}$ Histological features included stromal hypercellularity, stromal atypia, tumor microscopic margins, stromal mitotic activity, and stromal overgrowth. Patient follow-up was retrieved from medical records.

\section{Tissue Microarrays}

Tissue microarrays were constructed using the Manual Tissue Arrayer MTA-1 (Beecher Instruments, USA). Hematoxylin and eosin-stained slides were reviewed and three representative areas of interest with a high density of stromal cells were circled. The corresponding regions were marked on archival formalin-fixed, paraffin-embedded tissue blocks. The representative areas were then punched with a 2-mm diameter core and arrayed on three recipient blocks. An array was constructed with a maximum of 40 cores and a tonsil core was used as an orientation marker.

\section{Staining}

Sections of $4 \mu \mathrm{m}$ were fished onto charged slides (Microsystems Plus Slides, Leica, Germany). Immunohistochemistry was performed for CD117 using the BOND-MAX (Leica) automated system. Tissue sections were deparaffinized with Bond Dewax Solution, followed by antigen retrieval in ER solution 2 (pH 9.0) for $20 \mathrm{~min}$ at $100{ }^{\circ} \mathrm{C}$. Then, sections were treated with anti-CD117 antibody (A4502, Dako, Denmark) diluted in the ratio 1:400 for 20 min. Visualization was developed using the Bond Polymer Refine Detection (Leica) system. GIST was used as positive control and lymphocytes acted as negative control. For assessment of staining, slides were scanned with the ScanScope System (Aperio, CA) and viewed with ImageScope (Aperio). CD117 immunohistochemical staining was assessed in the cytoplasm and cytoplasmic membrane of stromal cells by two independent observers. Percentage of reactive stromal cells was recorded excluding the mast cells. Positivity of CD117 was defined when $1 \%$ or more stromal cells were reactive, taking into account the results of all three microarrays.
To further confirm that the CD117-positive cases were not confounded by mast cells, tissue microarray sections containing the positive cases were subjected to toluidine blue stain. Toluidine blue staining was performed with $0.5 \%$ toluidine blue working solution. After deparaffinization in xylene and graded alcohol, tissue sections were incubated in $0.5 \%$ toluidine blue working solution for $6 \mathrm{~min}$. Then, slides were immediately rinsed in changes of 95\% alcohol and dipped in absolute alcohol for 1 min. Finally, sections were cleared with xylene and mounted with DPX mounting media. Bone marrow tissue was used as a positive control. Presence of mast cells was defined by its red-purple (metachromatic) appearance amidst the toluidine blue-stained background.

\section{Mutation Analysis}

Nineteen cases were selected for mutation analysis on the basis of a prior study that included cases with and without events of recurrence/death on followup. ${ }^{14}$ Five to ten whole sections were cut at $10 \mu \mathrm{m}$ each for each case. DNA extraction was performed using the Ambion RecoverAll Total Nucleic Acid Isolation Kit (Life Technologies, USA) according to the manufacturer's protocol. DNA was quantified with PicoGreen (Life Technologies) assay and subjected for the OncoScan FFPE Express 2.0 Service (Affymetrix, CA). It interrogated 16 commonly reported CD117 mutations (Table 1) including exons 11,13 , and 17 using the molecular inversion probe assay.

\section{Statistical Analysis}

Statistical analysis was performed with SPSS for Windows, version 18. Chi-square and Fisher's exact tests were used to analyze the associations between CD117 expression and clinicopathological

Table 1 Panel of KIT mutations included in the OncoScan assay

\begin{tabular}{ccc}
\hline No. & KIT mutations & Exon number \\
\hline 1 & D52N & 2 \\
2 & W557R & 11 \\
3 & V559A & 11 \\
4 & V560D & 11 \\
5 & L576P & 11 \\
6 & F584S & 11 \\
7 & P585P & 11 \\
8 & K642E & 13 \\
9 & V654A & 13 \\
10 & T670I & 13 \\
11 & I798I & 13 \\
12 & D816Y & 17 \\
13 & N822K & 17 \\
14 & Y823D & 17 \\
15 & V825A & 17 \\
16 & E839K & 17 \\
\hline
\end{tabular}


parameters. Survival analysis was performed with Kaplan-Meier to estimate recurrence-free survival and overall survival, which were defined as the time from date of surgery to date of first relapse and death from phyllodes tumor, respectively, or to the last follow-up date for censored cases. Survival between groups was compared using the Log-rank test. A $P$-value of $<0.05$ was considered a significant result.

\section{Results}

A total of 272 cases of phyllodes tumor were diagnosed between January 2003 and December 2010-189 (70\%) were benign, 60 (22\%) were borderline, and 23 (8\%) were malignant. The overall patient age range was 15-79 years (mean and median 43 years). Tumor size range was $8-250 \mathrm{~mm}$ (mean $51 \mathrm{~mm}$, median $38 \mathrm{~mm}$ ). Overall, $28(10 \%)$ cases were positive for CD117-9 benign (5\%), 14 borderline $(23 \%)$, and 5 malignant (22\%) tumors (Figures 1a and b). Care was taken to discount
CD117-positive mast cells from being erroneously included among CD117-positive phyllodes tumors (Figures 1c and d). Proportion of positively stained stromal cells ranged from 1 to $5 \%$ with a mean of $1.4 \%$ and median of $1 \%$. Table 2 shows clinicopathological features of phyllodes tumors in association with CD117 positivity. CD117 expression was significantly associated with borderline/malignant tumors $(P<0.001)$. There was a significant association of CD117 positivity with increased stromal hypercellularity $(P=0.003)$, stromal atypia $(P=0.01)$, and stromal mitotic activity $(P<0.001)$, permeative microscopic margins $(P=0.002)$, and presence of hemorrhage $(P=0.001)$.

A total of 248 patients were included for the follow-up analysis after discounting those lost to follow-up and those in whom follow-up was $<3$ months. There were $24(10 \%)$ recurrences documented of which 18 were local and 6 were distant (Table 3). Mean and median times to recurrence were 27 and 21 months, respectively. Five deaths were documented-one benign, two borderline, and two malignant cases. The benign case recurred with

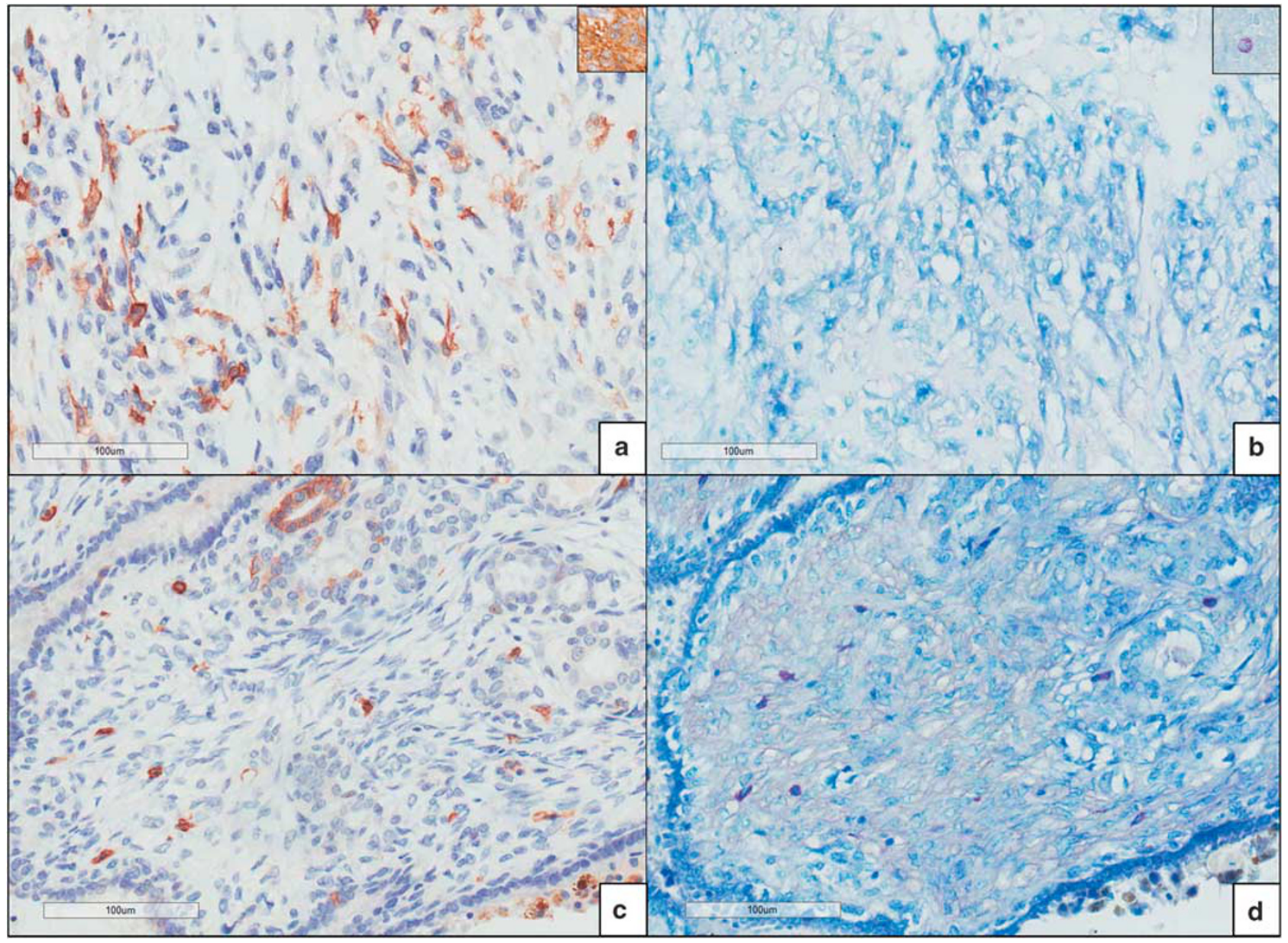

Figure 1 Example of a CD117-positive phyllodes tumor (a) with corresponding negative toluidine blue staining (b). Positive controls are shown in the top right inset. (c,d) An example of mast cells that are positive for both CD117 and toluidine blue staining. These cells are excluded in the assessment of CD117-positive stromal cells. 
Table 2 Clinicopathological characteristics of phyllodes tumors in association with CD117 stromal positivity

\begin{tabular}{|c|c|c|c|}
\hline $\begin{array}{l}\text { Clinicopathological } \\
\text { parameters }\end{array}$ & $\begin{array}{c}C D 117 \\
\text { negative, } \mathrm{n}(\%)\end{array}$ & $\begin{array}{c}C D 117 \\
\text { positive, } \mathrm{n}(\%)\end{array}$ & $\mathrm{P}$-value \\
\hline \multicolumn{4}{|c|}{ Age (mean 43 years, median 43 years, range $15-79$ ) } \\
\hline$\leq 43$ years & 124 (91) & $13(9)$ & \\
\hline$>43$ years & $120(89)$ & $15(11)$ & 0.694 \\
\hline \multicolumn{4}{|c|}{ Tumor size (mean $51 \mathrm{~mm}$, median $38 \mathrm{~mm}$, range $8-250 \mathrm{~mm}$ ) } \\
\hline$\leq 51 \mathrm{~mm}$ & $175(93)$ & $13(7)$ & \\
\hline$>51 \mathrm{~mm}$ & $69(82)$ & $15(18)$ & $0.009^{\mathrm{a}}$ \\
\hline \multicolumn{4}{|l|}{ Tumor grade } \\
\hline Benign & $180(95)$ & $9(5)$ & \\
\hline Borderline & $46(77)$ & $14(23)$ & \\
\hline Malignant & $18(78)$ & $5(22)$ & $<0.001^{\mathrm{a}}$ \\
\hline \multicolumn{4}{|c|}{ Stromal hypercellularity } \\
\hline Mild & $142(95)$ & $7(5)$ & \\
\hline Moderate & $87(82)$ & $19(18)$ & \\
\hline Marked & $15(88)$ & $2(12)$ & $0.003^{\mathrm{a}}$ \\
\hline \multicolumn{4}{|l|}{ Stromal atypia } \\
\hline Mild & $207(92)$ & $18(8)$ & \\
\hline Moderate & $31(82)$ & $7(18)$ & \\
\hline Marked & $6(67)$ & $3(33)$ & $0.01^{\mathrm{a}}$ \\
\hline \multicolumn{4}{|l|}{ Stromal mitosis } \\
\hline $0-4$ & $181(95)$ & $10(5)$ & \\
\hline $5-9$ & $39(85)$ & $7(15)$ & \\
\hline$>9$ & $24(69)$ & $11(31)$ & $<0.001^{\mathrm{a}}$ \\
\hline \multicolumn{4}{|l|}{ Stromal overgrowth } \\
\hline No & $218(91)$ & $21(9)$ & 0.059 \\
\hline Yes & $26(79)$ & $7(21)$ & \\
\hline \multicolumn{4}{|l|}{ Microscopic margin } \\
\hline Circumscribed & $192(93)$ & $14(7)$ & \\
\hline Permeative & $52(79)$ & $14(21)$ & $0.002^{\mathrm{a}}$ \\
\hline \multicolumn{4}{|c|}{ Pseudoangiomatous stromal hyperplasia } \\
\hline Absent & $236(90)$ & $26(10)$ & \\
\hline Present & $8(80)$ & $2(20)$ & 0.275 \\
\hline \multicolumn{4}{|l|}{ Myxoid change } \\
\hline Absent & $85(89)$ & $11(11)$ & \\
\hline Present & $159(90)$ & $17(10)$ & 0.679 \\
\hline \multicolumn{4}{|l|}{ Cystic change } \\
\hline Absent & $190(88)$ & $25(12)$ & \\
\hline Present & $54(95)$ & $3(5)$ & 0.221 \\
\hline \multicolumn{4}{|l|}{ Necrosis } \\
\hline Absent & $217(91)$ & $21(9)$ & \\
\hline Present & $27(79)$ & $7(21)$ & 0.062 \\
\hline \multicolumn{4}{|l|}{ Hemorrhage } \\
\hline Absent & $152(95)$ & $8(5)$ & \\
\hline Present & $92(82)$ & $20(18)$ & $0.001^{\mathrm{a}}$ \\
\hline
\end{tabular}

${ }^{\mathrm{a} D e n o t e s ~ s t a t i s t i c a l l y ~ s i g n i f i c a n t ~ r e s u l t s . ~}$

a borderline tumor with subsequent lung metastasis before death, whereas one patient with borderline tumor passed away from acute pancolitis, and the other patient with borderline tumor suffered lung metastasis leading to death. Details of the follow-up
Table 3 Details of 248 cases with follow-up

\begin{tabular}{lrrrrr}
\hline Diagnosis & \multirow{2}{*}{$\begin{array}{c}\text { CD117 } \\
\text { positive }\end{array}$} & $\begin{array}{c}\text { Local } \\
\text { recurrence }\end{array}$ & $\begin{array}{c}\text { Distant } \\
\text { recurrence }\end{array}$ & Death \\
\hline Benign & 169 & $7(4 \%)$ & $12(7 \%)$ & $1(1 \%)^{\mathrm{a}}$ & $1(1 \%)^{\mathrm{b}}$ \\
Borderline & 57 & $14(25 \%)$ & $4(7 \%)$ & $1(2 \%)$ & $2(4 \%)^{\mathrm{c}}$ \\
Malignant & 22 & $5(23 \%)$ & $2(9 \%)$ & $6(27 \%)^{\mathrm{a}}$ & $2(9 \%)^{\mathrm{d}}$ \\
\hline
\end{tabular}

${ }^{\mathrm{a}}$ local recurrence preceded distant recurrence.

$b_{\text {recurred with a borderline tumor with subsequent lung metastasis }}$ prior to death.

${ }^{\mathrm{C}}$ one patient passed away from acute pancolitis, and the other had lung metastasis prior to death.

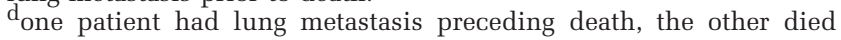
without recurrence.

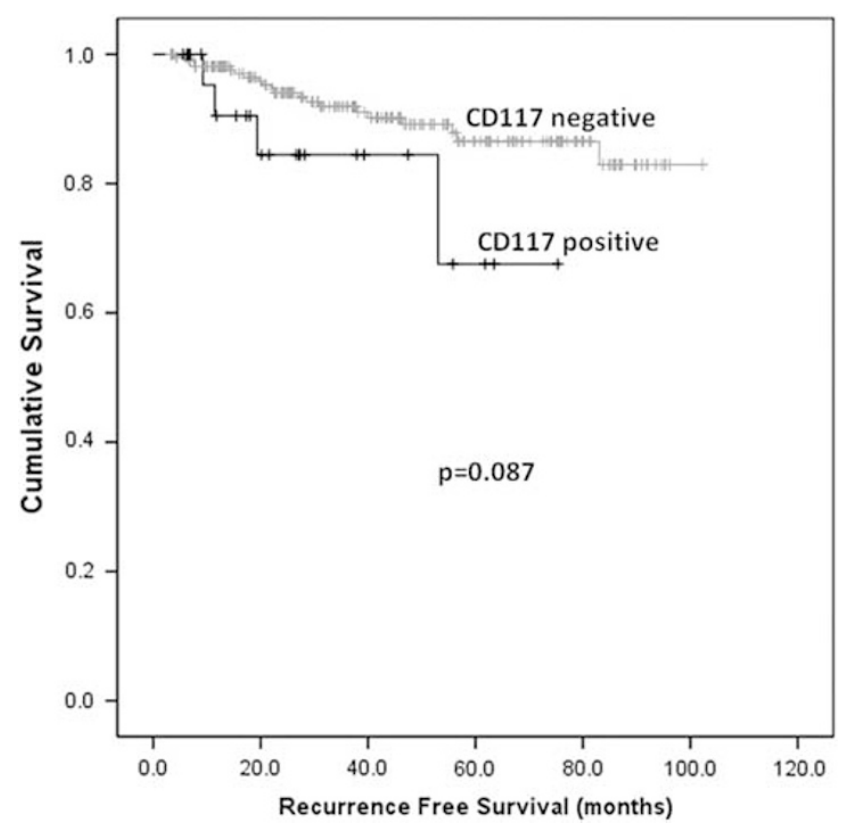

Figure 2 A trend of shorter recurrence-free survival was observed in patients with CD117-positive tumors.

were as previously described. ${ }^{15} \mathrm{~A}$ trend of shorter time to recurrence for tumors expressing CD117 was observed (Figure 2) compared with tumors not expressing CD117 $(P=0.087)$. In addition, we observed a higher percentage of CD117-expressing tumors in cases that metastasized $(25 \%)$ compared with those without metastasis $(10 \%)$, although this was not statistically significant. A worse prognosis was observed $(P=0.003)$ for tumors expressing CD117 compared with CD117-negative tumors (Figure 3).

Nineteen cases subjected to mutation analysis comprised seven benign, seven borderline, and five malignant cases. Details of the cases such as CD117 expression, prognosis, and epitheliumstromal composition are shown in Table 4. CD117 mutations (as shown in Table 1) were absent in all the cases. 


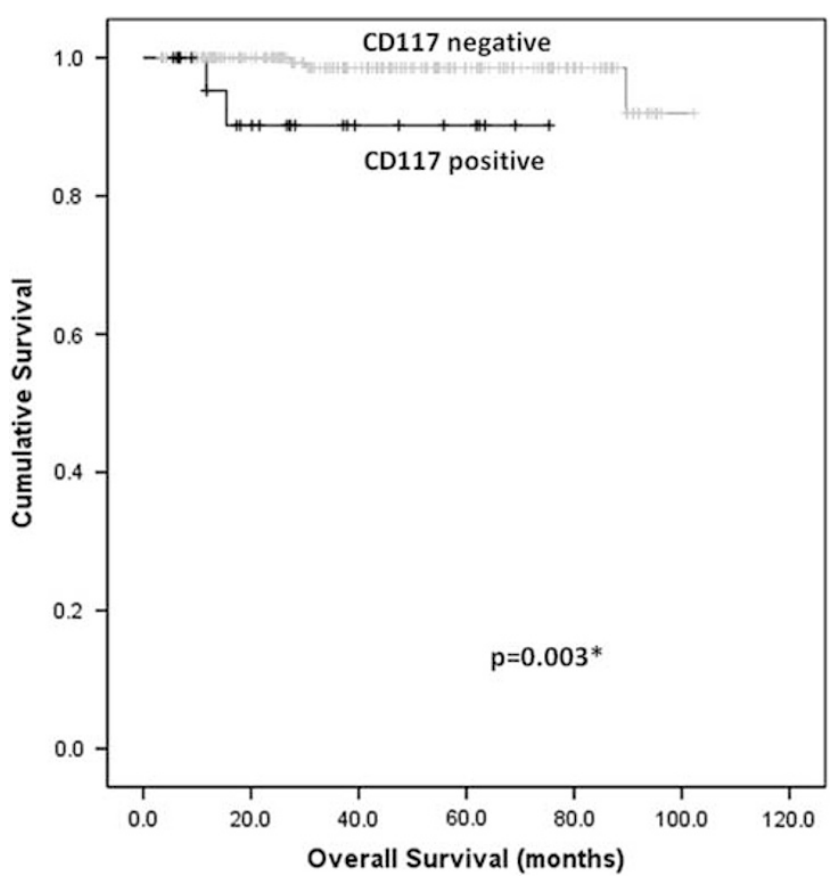

Figure 3 Patients with CD117-positive tumors experienced a worse overall survival compared to patients with CD117-negative tumors.

Table 4 Profile of tumors selected for mutation analysis via OncoScan

\begin{tabular}{lllcl}
\hline No. & Diagnosis & $\begin{array}{c}\text { CD117 } \\
\text { staining } \\
\text { status }\end{array}$ & $\begin{array}{c}\text { Epithelial- } \\
\text { stromal } \\
\text { percentage }\end{array}$ & \multicolumn{1}{c}{ Prognosis } \\
\hline 1 & Benign & Negative & $35-75$ & No recurrence \\
2 & Benign & Negative & $40-60$ & No recurrence \\
3 & Benign & Negative & $30-70$ & No recurrence \\
4 & Benign & Positive & $15-85$ & No recurrence \\
5 & Benign & Negative & $40-60$ & No recurrence \\
6 & Benign & Positive & $20-80$ & Local recurrence \\
7 & Benign & Negative & $20-80$ & Local recurrence \\
8 & Borderline & Negative & $10-90$ & No recurrence \\
9 & Borderline & Positive & $50-50$ & No recurrence \\
10 & Borderline & Negative & $20-80$ & No recurrence \\
11 & Borderline & Positive & $30-70$ & No recurrence \\
12 & Borderline & Positive & $15-85$ & No recurrence \\
13 & Borderline & Negative & $20-80$ & Local recurrence \\
14 & Borderline & Positive & $10-90$ & Bone metastasis \\
& & & & preceded death \\
15 & Malignant & Negative & $5-95$ & Lung metastasis \\
16 & Malignant & Negative & $0-100$ & Lung metastasis \\
17 & Malignant & Negative & $30-70$ & Lung metastasis \\
18 & Malignant & Negative & $0-100$ & Lung metastasis \\
& & & & preceded death \\
19 & Malignant & Positive & $1-99$ & Death without \\
& & & & recurrence \\
\hline & & & & \\
\hline & & & &
\end{tabular}

\section{Discussion}

Investigation of CD117 mutation status in phyllodes tumors was initiated in year 2000 by Chen et al. ${ }^{12}$ with a study sample size of 19 cases. The authors found two point mutations Q556X and N564S, involving the juxtamembrane domain (exon 11).
Mutations in this domain alter the autoinhibitory function of the receptor and lead to activation of the receptor even without the binding of a ligand. However, Jung et al. ${ }^{11}$ who also studied an Asian population found no mutations in exon 11, as well as in exons 9, 13, and 17 (commonly reported regions of activating mutations). Our findings concur with the latter observation, where no activating mutations were found. Several other studies of nonAsian populations also reported no activating mutations, despite scant findings of silent mutations or mutations of unknown significance. Sawyer et al. ${ }^{6}$ found a point mutation of L510M (exon 10) of unknown significance in one case. Carvalho et al. ${ }^{7}$ and Bose et al. ${ }^{8}$ reported a silent mutation of isoleucine 798 (exon 17) in two and one cases, respectively. Djordjevic et al. ${ }^{9}$ found no mutations in two cases of CD117-positive tumors.

Despite a lack of activating mutations observed in the KIT gene, overexpression of CD117 protein has previously been reported in phyllodes tumors. ${ }^{6,7}$ Several other reports have also shown an association of CD117 protein expression with increasing grade, ${ }^{11,16}$ with a few detailing preferential expression of CD117 in the malignant phenotype. $6,7,12,17,18$ However, there were also several groups that indicated no association between CD117 expression and tumor grade. ${ }^{8,9,19}$ In this study, we observed CD117 expression to be associated with borderline and malignant grade tumors. Toluidine blue staining was performed to rule out possible confounding contribution of mast cells, as previously suggested by Djodjervic et al. ${ }^{9}$ that the associations observed might have been a mast cell phenomenon. Toluidine blue was negative on cases that we defined as CD117 positive, reinforcing our initial observations.

The spectrum of results from the different groups could be attributed by the variable antibodies, staining protocols, and scoring criteria used (summarized in Table 5). There is no universal consensus currently as to which protocol and scoring criteria are the best. However, standardization of protocols between laboratories has been challenging and the antibodies used need to be optimized and validated individually. ${ }^{20}$ In this study, we employed Dako A4502, an antibody that is validated for diagnostic use and was evaluated previously by other authors to have high sensitivity and specificity across different tumors. ${ }^{21,22}$ As for scoring criteria, we used a $1 \%$ cutoff in view of the fact that CD117 is not normally expressed in breast stromal cells. ${ }^{23}$ Hence, even a low percentage of protein expression could indicate an abnormal state. This is exemplified by our study in which cases that were CD117 positive on immunohistochemistry demonstrated a low percentage of positive cells. Although this may be partly due to the use of tissue microarrays that reflect only a small proportion of the entire tumor, we have previously shown that tissue microarrays provide a dependable replication of phyllodes tumors in terms of biomarker expression. ${ }^{24}$ 
Table 5 Summary of investigations of CD117 expression and mutation status in phyllodes tumors

\begin{tabular}{|c|c|c|c|c|c|c|}
\hline Authors, reference & $\mathrm{N}$ & Antibody and dilution & Scoring criteria & CD117 expression & Mutation status & Follow-up \\
\hline Chen et al. ${ }^{12}$ & 19 & Chemicon clone K69 1:100 & $\geq 10 \%$ & $\begin{array}{l}\text { Associated with } \\
\text { malignant grade }\end{array}$ & $\begin{array}{l}\text { Q556X (exon 11) } \\
\text { and N564S (exon 11) } \\
\text { in one case each }\end{array}$ & NA \\
\hline Sawyer et al. ${ }^{6}$ & 30 & Novocastra 1:20 & Intensity $\geq 1$ & $\begin{array}{l}\text { Associated with } \\
\text { malignant grade }\end{array}$ & $\begin{array}{l}\text { L510M (exon 10) in } \\
\text { one case }\end{array}$ & NA \\
\hline Tse et al. ${ }^{16}$ & 179 & Novocastra 1:40 & $\begin{array}{l}\geq 20 \% \text { stromal cells of } \\
\text { moderate-to-strong staining }\end{array}$ & $\begin{array}{l}\text { Correlated with } \\
\text { increasing grade }\end{array}$ & NA & $\begin{array}{l}\text { Not correlated } \\
\text { with recurrence }\end{array}$ \\
\hline Carvalho et al. ${ }^{7}$ & 19 & Novocastra 1:60 & $\geq 25 \%$ & $\begin{array}{l}\text { Associated with } \\
\text { malignant grade }\end{array}$ & $\begin{array}{l}\text { Silent mutation } \\
\text { Isoleucine } 798 \\
\text { (exon 17) in two cases }\end{array}$ & NA \\
\hline Tan et al..$^{10}$ & 335 & Dako A4502 1:250 & Any unequivocal staining & $\begin{array}{l}\text { Associated with } \\
\text { tumor grade }\end{array}$ & NA & $\begin{array}{l}\text { Expression correlated } \\
\text { with recurrence }\end{array}$ \\
\hline Esposito et al. ${ }^{117}$ & 16 & Dako polyclonal 1:100 & $\begin{array}{l}\text { Combined immunoreactive } \\
\text { score } \geq 1\end{array}$ & $\begin{array}{l}\text { Associated with } \\
\text { tumor grade }\end{array}$ & NA & $\begin{array}{l}\text { Not correlated with } \\
\text { recurrence }\end{array}$ \\
\hline Yonemori et al. ${ }^{19}$ & 41 & $\begin{array}{l}\text { Dako A4502 Dilution } \\
\text { not specified }\end{array}$ & $\begin{array}{l}>10 \% \text { of at least } \\
\text { moderate intensity }\end{array}$ & $\begin{array}{l}\text { None of the cases } \\
\text { were positive }\end{array}$ & NA & $\begin{array}{l}\text { No positive cases for } \\
\text { correlation with six } \\
\text { distant recurrences }\end{array}$ \\
\hline Djordjevic et $a l^{9}$. & 47 & Zymed 1:400 & $>0 \%$ & No correlation & $\begin{array}{l}\text { Not detected in two } \\
\text { CD117-positive tumors }\end{array}$ & NA \\
\hline Bose et al. ${ }^{8}$ & 17 & Dako 1:50 & $\geq 5 \%$ & No correlation & $\begin{array}{l}\text { Silent mutation } \\
\text { Isoleucine } 798 \\
\text { (exon 17) in one case }\end{array}$ & NA \\
\hline Jung et al. ${ }^{11}$ & 67 & Dako polyclonal 1:300 & $>10 \%$ & $\begin{array}{l}\text { Correlated with } \\
\text { increasing grade }\end{array}$ & $\begin{array}{l}\text { None detected in } \\
\text { subset of } 28 \text { samples }\end{array}$ & $\begin{array}{l}\text { Expression associated } \\
\text { with recurrence }\end{array}$ \\
\hline Noronha et al. ${ }^{18}$ & 33 & Biocare clone Y145 1:100 & $\geq 20 \%$ & $\begin{array}{l}\text { Differentially } \\
\text { expressed in } \\
\text { malignant grade }\end{array}$ & NA & NA \\
\hline
\end{tabular}

NA- Experiment not performed/Data not available.

We observed a trend of shorter recurrence-free survival in CD117-positive cases, despite not being statistically significant. This trend corroborates our previous findings where CD117 stromal positivity was correlated with recurrence. ${ }^{10}$ In this study, we also observed a higher percentage of CD117-positive cases among tumors that metastasized despite not being significant statistically. In addition, a significant poorer survival outcome was observed in patients with CD117-positive tumors. The limitation with all of the above findings is the small number of events that were documented. Nevertheless, it is worthwhile to note that all these traits point to a poorer clinical outcome of CD117-expressing tumors, which suggest their underlying aggressive nature.

Investigations into CD117 protein expression and mutation status were largely motivated by the success of a tyrosine kinase inhibitor in patients with GISTs. There has been previous suggestion that the stromal component of phyllodes tumors bear some similarities to GISTs such as the spindled nature and spectrum of behavior from benign to malignant. ${ }^{7}$ However, recent insights into the roles of CD117 in cancer shed important light on the different types of CD117-expressing tumors. Broadly, CD117-expressing tumors can be classified into two main groups: ${ }^{25}$ (1) those characterized by gain-offunction (activating) CD117 mutations and derived from cells that normally express CD117. In these cases, CD117 has a central pathogenetic role in neoplasm initiation; (2) those with rare occurrence of CD117 mutations, in which tumors are composed of cells that normally do not express CD117. CD117 has a passive role in this group of tumors and its expression is acquired during tumor progression. This may explain the lack of mutations found in phyllodes tumors as compared with GISTs. GISTs arise from the oncogenic transformation of interstitial cells of Cajal that normally express high levels of CD117. Comparatively, the stromal component of phyllodes tumors, which likely arises from breast mesenchymal tissue, does not usually express CD117 under normal circumstances.

In conclusion, we report an association of CD117 protein expression with borderline/malignant tumors and with worse pathologic parameters. We also observed a worse prognosis in patients with CD117 immunohistochemically positive tumors despite the absence of activating mutations. The lack of activating mutations suggests that the therapeutic option of using a tyrosine kinase such as imatinib in patients with malignant phyllodes tumors is unlikely to be effective. Nonetheless, the associations observed with tumor grade and poorer prognosis are real phenomena that suggest a role of CD117 in the biological behavior of breast phyllodes tumors.

\section{Disclosure/conflict of interest}

The authors declare no conflict of interest.

\section{References}

1 Lennartsson J, Rönnstrand L. Stem cell factor receptor/ c-Kit: from basic science to clinical implications. Physiol Rev 2012;92:1619-1649. 
2 Corless C, McGreevey L, Haley A, et al. KIT mutations are common in incidental gastrointestinal stromal tumors one centimeter or less in size. Am J Pathol 2002;160:1567-1572.

3 Gavert N, Shvab A, Sheffer M, et al. c-Kit is suppressed in human colon cancer tissue and contributes to L1mediated metastasis. Cancer Res 2013;73:5754-5763.

4 Hodi F, Corless C, Giobbie-Hurder A, et al. Imatinib for melanomas harboring mutationally activated or amplified KIT arising on mucosal, acral, and chronically sun-damaged skin. J Clin Oncol 2013;31:3182-3190.

5 Tan PH, Tse G, Lee A, et al. Fibroepithelial tumors, In: Lakhani SR, Ellis IO, Schnitt SJ, Tan PH, van de Vijver MJ (eds) WHO Classification of Tumors of the Breast, 4th edn. International Agency for Research on Cancer: Lyon; 2012, pp 142-147.

6 Sawyer EJ, Poulsom R, Hunt FT, et al. Malignant phyllodes tumors show stromal overexpression of c-myc and c-kit. J Pathol 2003;200:59-64.

7 Carvalho S, e Silva AO, Milanezi F, et al. c-KIT and PDGFRA in breast phyllodes tumors: overexpression without mutations? J Clin Pathol 2004;57:1075-1079.

8 Bose P, Dunn S, Yang J, et al. c-Kit expression and mutations in phyllodes tumors of the breast. Anticancer Res 2010;30:4731-4736.

9 Djordjevic B, Hanna WM. Expression of c-kit in fibroepithelial lesions of the breast is a mast cell phenomenon. Mod Pathol 2008;21:1238-1245.

10 Tan PH, Jayabaskar T, Yip G, et al. p53 and c-kit (CD117) protein expression as prognostic indicators in breast phyllodes tumors: a tissue microarray study. Mod Pathol 2005;18:1527-1534.

11 Jung C, Suh K, Lee J, et al. Mutation-free expression of C-Kit and PDGFRA in phyllodes tumors of the breast. J Breast Cancer 2010;13:257.

12 Chen CM, Chen CJ, Chang CL, et al. CD34, CD117, and actin expression in phyllodes tumor of the breast. J Surg Res 2000;94:84-91.

13 Tan PH, Thike AA, Tan WJ, et al. Predicting clinical behaviour of breast phyllodes tumors: a nomogram based on histological criteria and surgical margins. J Clin Pathol 2012;65:69-76.

14 Tan WJ, Lai JC, Thike AA, et al. Novel genetic aberrations in breast phyllodes tumors: comparison between prognostically distinct groups. Breast Cancer Res Treat 2014;145:635-635.

15 Tan WJ, Thike AA, Bay BH, et al. Immunohistochemical expression of homeoproteins Six1 and Pax3 in breast phyllodes tumors correlates with histological grade and clinical outcome. Histopathology 2013;64: 807-817.

16 Tse GMK, Putti TC, Lui PCW, et al. Increased c-kit (CD117) expression in malignant mammary phyllodes tumors. Mod Pathol 2004;17:827-831.

17 Esposito NN, Mohan D, Brufsky A, et al. Phyllodes tumor: a clinicopathologic and immunohistochemical study of 30 cases. Arch Pathol Lab Med 2006;130: 1516-1521.

18 Noronha Y, Raza A, Hutchins B, et al. CD34, CD117, and Ki-67 expression in phyllodes tumor of the breast: an immunohistochemical study of 33 cases. Int J Surg Pathol 2011;19:152-158.

19 Yonemori K, Hasegawa T, Shimizu C, et al. Correlation of p53 and MIB-1 expression with both the systemic recurrence and survival in cases of phyllodes tumors of the breast. Pathol Res Pract. 2006;202:705-712.

20 Loughrey MB, Trivett M, Beshay $\mathrm{V}$, et al. KIT immunohistochemistry and mutation status in gastrointestinal stromal tumors (GISTs) evaluated for treatment with imatinib. Histopathology 2006;49:52-65.

21 Lucas DR, Al-Abbadi M, Tabaczka P, et al. c-Kit Expression in desmoid fibromatosis: comparative immunohistochemical evaluation of two commercial antibodies. Am J Clin Pathol 2003;119:339-345.

22 Went PT. Prevalence of KIT expression in human tumors. J Clin Oncol 2004;22:4514-4522.

23 Kondi-Pafiti A, Arkadopoulos N, Gennatas C, et al. Expression of c-kit in common benign and malignant breast lesions. Tumori 2010;96:978-984.

24 Ho SK, Thike AA, Cheok PY, et al. Phyllodes tumors of the breast: the role of CD34, vascular endothelial growth factor and $\boldsymbol{\beta}$-catenin in histological grading and clinical outcome. Histopathology 2013;63: 393-406.

25 Pittoni P, Piconese S, Tripodo C, et al. Tumor-intrinsic and -extrinsic roles of c-Kit: mast cells as the primary off-target of tyrosine kinase inhibitors. Oncogene 2011;30:757-769. 